\title{
Information Uncertainty and Momentum Phenomenon Amidst Market Swings: Evidence From the Chinese Class A Share Market
}

\author{
Yuan Wu' ${ }^{1}$. Taufiq Choudhry
}

Published online: 14 June 2018

(C) The Author(s) 2018

\begin{abstract}
This paper empirically investigates how firm-level information uncertainty impacts momentum profits in the Chinese Class A share market. We employ seven different factors to gauge the degree of firm-level information uncertainty-firm size, firm age, analysts' coverage, return volatility, dispersion in analysts' earnings forecast, trading volume, and the quality/strength of corporate governance (free float ratio). We find evidence showing that information uncertainty has an amplifying effect over the momentum profits, and the amplifying effect is more pronounced over the time periods following DOWN market state over the sample period from January 1996 to December 2013. The robustness of the empirical evidence is warranted by a risk-adjustment test based on the FF3F model and Wang and Xu's (Financ Anal J 60(6):65-77, 2004) FF3F model, a sub-period analysis, and a different definition of market states. The empirical findings can provide an important reference point for international and domestic investors when adjusting investment strategies and portfolio positions in relatively volatile financial markets such as the Chinese stock market.
\end{abstract}

Keywords Information uncertainty - Chinese Class A share market - Amplifying effect $\cdot$ Momentum phenomenon $\cdot$ Asset pricing

JEL Classification $\mathrm{G} 12 \cdot \mathrm{G} 14 \cdot \mathrm{G} 15$

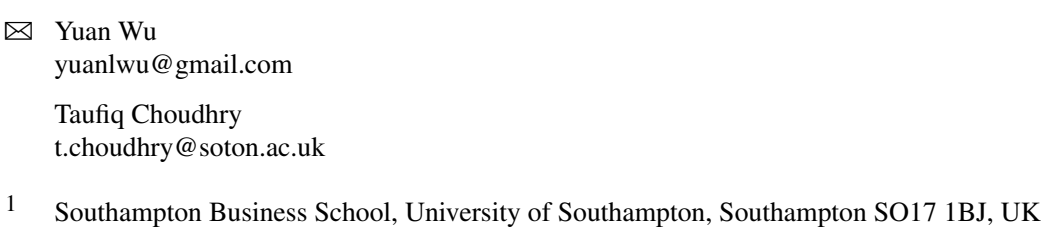




\section{Introduction}

Since the publication of Jegadeesh and Titman's (1993) seminal work on the momentum phenomenon, the discussions revolving around the anomalous effect have been capturing the attention of many academics and financial industry practitioners. Some empirical results show the existence of the momentum profits around the globe, challenging the validity of the semi-strong form of the Efficient Market Hypothesis (EMH) (Fama 1965), while the efficient market hypothesis proponents devoted monumental effort to rationalise the anomalous effect. In this line of research, a couple of recent studies (Jiang et al. 2005; Zhang 2006) investigated the impact of firm-level information uncertainty (IU hereafter) on the momentum phenomenon). Specifically, they documented a superior performance of momentum trading by investing in firms with higher degree of information uncertainty in the setting of the US stock markets. Our study extends the seminal work of Jiang et al. (2005) and Zhang (2006) by studying the dynamics of the "interaction effect" amid market swings in the unique setting of the Chinese Class A share market. Aside from the prominent position of the Chinese economy $^{2}$ in the global economy, we focus on the setting of the Chinese stock market due to its unique characteristics such as the large proportion of retail investors and the split between tradable shares and non-tradable shares. We employ a set of seven factors-firm size, firm age, return volatility, dispersion in analysts' earnings forecast, trading volume, and the strength of corporate governance - to measure firm-level information uncertainty. Subsequently, we apply a two-way sorting approach to study the interaction between firm-level information uncertainty and conditional momentum profits (post-UP and -DOWN market states) during the time horizon from January 1996 to December 2013. We find superior momentum returns within investment of high IU firms, suggesting that IU has an amplifying effect over momentum effect. Moreover, the amplifying effect is more pronounced over time periods following DOWN market state. The results are resilient to a risk adjustment procedure based on both the FF3F model and Wang and Xu's (2004) FF3F model, ${ }^{3}$ a sub-period analysis, and a different definition of market state (prior-24-month market average return).

This study extends the seminal work by Jiang et al. (2005) and Zhang (2006) on the "interaction effect" by using the strength of corporate governance to gauge firmlevel IU, and by further examining the interaction of the IU and momentum profits conditional on different market states. In addition, the role of the strength of corporate governance as a risk factor in Wang and Xu's (2004) FF3F model is empirically studied during the risk adjustment procedure. To the best of the author's knowledge, no previous study has empirically investigated the impact of information uncertainty over momentum profits and the role of corporate governance in measuring firm-level information uncertainty and risk in the context of the Chinese Class A share market. The results from this study are a valuable addition to the existing evidence from an array of studies focusing on the unconditional price momentum in the Chinese stock market

\footnotetext{
1 The term "Interaction effect" was introduced by Jiang et al. (2005), indicating a positive relationship between firm-level information uncertainty and price momentum profits.

2 The Chinese stock market accounted for $40.37 \%$ of GDP in the Chinese economy in 2008.

3 The traditional value effect factor is supplanted with a corporate governance factor.
} 
(Kang et al. 2002; Naughton et al. 2008). The remainder of the paper is organised as follows: Sect. 2 outlines the relevant literature. The hypotheses development is presented in Sect. 3. While Sect. 4 describes sample dataset and methodology, Sect. 5 presents the empirical findings of this study. Section 6 describes the robustness test result, and Sect. 7 concludes the study.

\section{Literature Review}

The seminal work of this line of research is carried out by Jiang et al. (2005) in the US stock markets. Differing from the previous information uncertainty (IU)related studies where researchers traditionally interpret information uncertainty as an indication of information asymmetry, Jiang et al. (2005) hypothesise that information uncertainty represents the difficulty of estimating firms' value, and thereby employ four variables-Firm Age, Return Volatility, Average Daily Turnover, and the Duration of its future cash flows - to proxy for the degree of IU. In their research, Jiang et al. (2005) reason that a greater degree of firm-level information uncertainty associated with stocks can potentially accentuate the magnitude of momentum profits under the information-uncertainty investor's overconfidence arbitrage-costs paradigm. ${ }^{4}$ Through analysing the interactions between the IU factor with price momentum, with earnings momentum, and with industry distribution respectively, they find the empirical evidence supports their hypothesis - the implementation of momentum trading strategies within stocks associated with high IU level significantly improved the momentum profits. From an empirical perspective, Jiang et al. (2005) contend that the trading strategy that emphasises the impact of the momentum-related signals on high-IU firms and impact of value-related signals on low-IU firms could strengthen the profitability of portfolio investment. Extending Jiang et al.'s (2005) work, Zhang (2006) adopts a slightly different approach to gauge the degree of information uncertainty factor. Locating the bedrock of his research hypothesis on the heuristic bias - specifically, overconfidence-as suggested by evidence found in previous behavioural finance studies (Daniel et al. 1998), Zhang (2006) selects a set of factors comprising firm size, firm age, analyst coverage, dispersion in analyst earnings forecasts, stock volatility, and cash flow volatility in an attempt to best proxy for the level of information uncertainty ${ }^{5}$ associated with companies listed in the US stock market. Forming portfolios based on different information uncertainty proxies, Zhang (2006) finds that all the empirical evidence unanimously suggests that a higher IU level associated with stocks following good/bad news magnifies the profitability of momentum trading strategies. This indirectly indicates that the momentum effect can be largely attributed to how quickly share prices adjust to news to reflect the company's fundamental value. Specifically, the momentum profits are noticeably larger among stocks/portfolios associated with high levels of information uncertainty.

\footnotetext{
4 "The level of information uncertainty is positively correlated with a pervasive form of decision bias (investor overconfidence), and that it is also positively correlated with arbitrage costs (in particular, the prevalence of information cascades)" (Jiang et al. 2005: 217).

${ }^{5}$ Zhang (2006: 105) defines information uncertainty as "ambiguity with respect to the implications of new information for a firm's value...".
} 
In addition, the intricate relationship between the strength of corporate governance and the performance of stocks for corresponding firms has been well documented in the literature. Gompers et al. (2003) construct a "Governance Index" using data taken from the Investor Responsibility Research Center (IRRC) and find that "corporate governance is strongly correlated with stock returns during the 1990s" (Gompers et al. 2003: 144). Drobetz et al. (2004) test Gompers et al.'s (2003) hypothesis on the German financial market using a broad corporate governance rating (CGR) to measure corporate quality of the firms and find that "better corporate governance is highly correlated with better operating performance, higher stocks returns and higher market valuation" (Drobetz et al. 2004: 270). In the setting of the Chinese stock market, Wang and $\mathrm{Xu}$ (2004) employ corporate governance-measured by residual free-float ratio - to replace the value effect factor of the traditional FF3F model as one of the risk factors in a modified version of Fama and French's 1993 three-factor model and document the fact that the corporate governance factor (free-float ratio) "significantly increased the explanatory power of the market model" (Wang and Xu 2004: 65).

Additionally, the quality/strength of firm-level corporate governance has been entrenched as a suitable proxy for firm-level IU. Bushman and Smith (2001) empirically explore the interrelation between information uncertainty and corporate governance practices and show that the quality of corporate governance can reflect the level of information uncertainty associated with firms in the corporate markets. Magnan and $\mathrm{Xu}$ (2008) show that poor quality of corporate governance practice (no or less information disclosure) can trigger a higher level of firm-specific information uncertainty.

\section{Hypothesis Development}

This study adopts the entrenched definition of firm-level information uncertainty- "the degree to which a firm's value can be reasonably estimated by even the most knowledgeable investors at reasonable costs" (Jiang et al. 2005: 185) and "the ambiguity with respect to the implications of new information for a firm's value" (Zhang 2006: 105). According to the theoretical framework of judgmental heuristics, economic agents are inclined to introduce more optimistic bias into their decisionmaking procedures under the conditions of greater information uncertainty (Armor and Taylor 1998). With judgments hamstrung by lack of relevant information and the afore-mentioned optimistic bias, investors are predisposed to become involved in an evaluative judgmental procedure of information processing (Armor and Taylor 1998; Schwarz 1990), characterised by frequent practice of intuitive heuristics such as affective and prototype heuristics of System 1 (intuitive) of two cognitive systems (Kahneman and Frederick 2002). The investors' participation in the evaluative judgmental process fosters and heightens the influence of various behavioural biases such as overconfidence (Daniel et al. 1998), conservatism (Barberis et al. 1998), underconfidence (Du 2002) and under-reaction (Hong and Stein 1999) over the momentum phenomenon. A higher degree of information uncertainty is expected to have an amplifying effect upon momentum returns (Grinblatt et al. 1995; Kurov 2008; Nofsinger and Sias 1999). 
In light of various established behavioural theories revolving the momentum phenomenon, we pulled together four contemporary behavioural theory frameworks while exploring the influence of information uncertainty over momentum returns: (1) Daniel et al. (1998) propose a behavioural model where investors are assumed to be quasirational and overconfident, and suggest that it is the investors' overreaction driven by human cognitive biases-overconfidence, self-attribution bias and confirmation bias - that leads to the momentum phenomenon observed in the financial market; (2) Inspired by psychological evidence such as representativeness bias (Tversky and Kahneman 1974) and confirmation bias (Gilovich 1993), Barberis et al. (1998) construct a model consisting of one representative market investor and one security, where the representative investor's sentiment directly affects the security's price in the fictional market. They claim that the momentum phenomenon stems from the investors' underreaction to earnings information in the financial market; (3) Hong and Stein (1999) extended two prior works (Barberis et al. 1998; Daniel et al. 1998) by constructing a behavioural theory on the behavioural interaction between two different types of agent as opposed to the focus on the behaviour of one single representative agent employed by Barberis et al. (1998) and Daniel et al. (1998). According to Hong and Stein's (1999) theory, all market investors are assumed to be "boundedly rational" (Hong and Stein 1999: 2144), yet can be divided into two distinctive groups- "newswatcher" and "momentum trader". They subsequently postulate that it is under-reaction by "newswatchers" towards private information signals that drives and lies at the heart of the momentum phenomenon in the stock market; (4) Du (2002) proposes a behavioural model on the premise of heterogeneity in investors' self-confidence. The momentum phenomenon is largely believed to be driven by investors' under-reaction to public information, signalling a permanent change in the fundamental value of assets (Hong and Stein 1999). Du nominates investors' hesitation during the decision-making process as the driving force behind the momentum phenomenon.

Proposition 1 Information uncertainty, proxied by seven different factors comprising firm size, firm age, analysts' coverage, return volatility, dispersion in analysts' earnings forecast (DISP), trading volume, and the quality/strength of corporate governance (free float ratio), amplifies the returns of the (Ranking $=6$ months, Holding $=6$ months) momentum strategy in the Chinese Class A share market.

Under the theoretical framework of heuristics and biases traditions (Tversky and Kahneman 1974), the vast majority of Chinese stock market participants (retail investors) (Kang et al. 2002) are inclined to embrace the bearish view concerning the outlook of stock returns (Fisher and Statman 2002) following a market downside movement, which is a reflection of retail investors' persistent sombre sentiment (Brown and Cliff 2004, Fisher and Statman 2000). In the face of a greater degree of information uncertainty, the negative sentiment of Chinese retail investors heightens their perception of risk (Schwarz 1990). This leads to the under-reaction toward firm-specific news induced by investors with low confidence (Du 2002) and in turn results in more profound momentum profits among high IU stocks over the time peri- 
ods following DOWN market states. ${ }^{6}$ Similarly, another parallel theory points to the same conjecture. Retail investors are pessimistic over the dim outlook of the market during post-down market periods. Being preoccupied by investors' concern over heightened IU provokes the evaluative judgment process involving frequent practice of intuitive heuristics (Schwarz 1990) such as the affective, availability heuristics of System 1 (intuitive) of two cognitive systems (Frederick 2002; Kahneman and Frederick 2002). As a result, investors' decisions are subject to the pervasive influence of different behavioural biases such as overconfidence, conservatism, under-confidence, all of which engender larger momentum profits during post-market slides (Barberis et al. 1998; Daniel et al. 1998; Du 2002; Hong and Stein 1999). During the time periods following market run-ups, Asian investors are less prone to the influence of different forms of heuristic bias for the repressed individualism in Asian culture in their decision-making processes. This attribute subsequently depresses the significance of the momentum effect in Asian financial markets (Chui et al. 2010). Taken together, we form the second proposition.

Proposition 2 The amplifying effect of information uncertainty over momentum return of the $(R=6, H=6)$ momentum trading strategy is more pronounced over the time periods following DOWN market state.

\subsection{Measurement of firm-level information uncertainty}

A few researchers (Jiang et al. 2005; Zhang 2006) have studied the impact of information uncertainty over the momentum profits; yet, to date, there is no consensus on the most suitable set of variables to measure firm-level information uncertainty (Schultz 2005). In view of Zhang (2006) and Jiang et al. (2005)'s seminal works and prior empirical evidence indicating the intricate relationship between the strength of corporate governance, firm value, and information uncertainty (Cai et al. 2006; Gompers et al. 2003; Magnan and Xu 2008; Wang and Xu 2004), we employ a group of seven proxy factors to gauge the degree of firm-level information uncertainty:

1. Firm size is measured by a stock's market capitalisation before the ranking period. Firms of small capitalisation size are associated with a less diversified business model, higher leverage level, and are susceptible to the obscuring of information accessibility (Chan and Chen 1991).

2. Firm age is measured by the number of days prior to the ranking period after a stock gets listed or first appears in the database. Firms with a relatively short history in the stock market tend to receive limited attention from analysts and investing public, exposing them to information deficit (Jiang et al. 2005; Zhang 2006).

\footnotetext{
${ }^{6}$ Elsewhere in the literature, one line of psychological study shows that people tend to appear underconfident in decision making when facing high information uncertainty by misplacing weights on the strength of the evidence upon which the decisions are drawn (Griffin and Tversky 1992), leading to the under-reaction in share price (Du 2002) and therefore giving rise to increasingly large momentum profits under a greater information uncertainty.
} 
3. Analysts' coverage is measured by the residual ${ }^{7}$ from regressing the number of analysts covering the firm in the year before the ranking period against the market capitalisation of the corresponding firm to mitigate the confounding effect of the firm size and analysts' coverage ${ }^{8}$ documented by Bhushan (1989). The information on firms with less analysts' coverage tends to diffuse at a slower pace (Hong and Stein 1999).

4. Return volatility is measured by the standard deviation of the monthly returns of a stock over 6 months prior to the ranking period. Several existing empirical studies established a positive association between return volatility of share price and the degree of firm's value ambiguity (e.g. Magnan and Xu 2008).

5. The dispersion of analysts' opinion on earnings forecast "reflect[s] the information uncertainty each security bears" (Graham and Zweig 2003: 238) and is measured by the "standard deviation of analysts' earnings forecasts scaled by prior year-end stock price to mitigate heteroskedasticity" (Zhang 2006: 110). The divergence of analysts' opinion on share value signifies firm-level information uncertainty (Diether et al. 2002; Dische 2002).

6. Trading volume is estimated by the turnover ratio ${ }^{9}$ of a stock prior to the ranking period. According to the liquidity hypothesis (Amihud and Mendelson 1986), thinly-traded stocks bear more risk and are associated with firm-level information uncertainty.

7. The strength of corporate governance is measured by free float ratio ${ }^{10}$ (Wang and $\mathrm{Xu}$ 2004). Specifically, the free float ratio is calculated by taking the ratio of the number of shares in a listed firm that is free to trade among investors and the total number of shares issued by a company. A negative association between the strength of corporate governance practice and the degree of firm-level information uncertainty has been documented by a slew of empirical studies (Bushman and Smith 2001; Cai et al. 2006; Gillan et al. 2006).

\section{Sample Dataset and Methodology}

\subsection{Sample Dataset}

The data used in this research are kindly provided by Guotai Junan Securities Co. Ltd. ${ }^{11}$ (GTJA) through their database provider, Shanghai Wind Information Co. Ltd. ${ }^{12}$

\footnotetext{
7 This approach is similar to the procedure employed by Hong et al. (2000) and McKnight and Hou (2006).

8 The rationale of the cofounding effect is rather trivial: large cap-firms tend to draw more attention from the analysts, thus resulting in a positive correlation between the firm size factor and analysts' coverage factor (Bhushan 1989).

9 The turnover ratio is calculated by taking the ratio between the number of shares changing hands each day and the number of total shares outstanding for the stock at the end of the day (estimated based on quarterly data due to data availability).

${ }^{10}$ Free float ratio is defined as "the ratio of shares in a public company that are freely available to the investing public to total company shares" (Wang and Xu 2004: 65).

11 GTJA. July, 2015. http://www.gtja.com/ygygtja/gygtja.html.

12 Wind Financial Database. July, 2015.http://www.wind.com.cn/en/product/windDB.htm.
} 
The sample period adopted for the research is from January 1996 to December 2013, covering 216 months in total. The types of data used for the analysis in this study can be listed out as follows: (1) The monthly price data ${ }^{13}$ of the Chinese Class A shares in the Shanghai Stock Exchange (SHSE hereafter) and the Shenzhen Stock Exchange SZSE (SZSE hereafter) (excluding dividends and interest); (2) Trading volumes of Chinese Class A shares listed in the SHSE and the SZSE; (3) Turnover ratios of the Chinese Class A shares listed in the SHSE and the SZSE; (4) the number of tradable shares of the Chinese Class A shares listed in the SHSE and the SZSE; (5) Monthly market capitalisation of the Chinese Class A shares listed in the SHSE and the SZSE; (6) Annual data of the number of days stocks have been listed in the Chinese Class A share market; (7) Annual data on the number of financial analysts following and issuing earnings' estimates for Share A stocks in the Chinese Class A share market; (8) Semi-annual data of the differences in opinions between analysts' earnings forecasts (EPS) ${ }^{14}$ of the Chinese Class A share market; (9) Monthly China one-year-time deposit rate; (10) Monthly index price data for Shanghai composite, A index; and (11) Monthly index price data for Shenzhen component, A index.

Seven different factors (firm size, firm age, return volatility, trading volume, analyst coverage, corporate governance, dispersion in analysts' earnings forecast) are employed to examine the impact of firm-level information uncertainty over momentum profits. Firm size is gauged by the market capitalisation (in million yuan ${ }^{15}$ ) of each stock at the end of month t. Firm age is measured by the number of days since a stock gets listed or first appears in the database. Return volatility is the standard deviation of monthly returns of each listed stock over 6 months prior to the beginning of the ranking period. Trading volume is estimated by the turnover ratio of each listed stock at the end of month t. Analysts' coverage is measured by the number of analysts covering the firm in the year prior to the ranking period. The strength of corporate governance is proxied by the free float ratios ${ }^{16}$ of listed firms prior to the beginning of the ranking period. Dispersion in analysts' earnings forecast (DISP) is measured by the standard deviation of analysts' earnings forecasts scaled by prior year-end stock price.

As shown in Table 1, the average firm size of the Chinese Class A shares, measured by firm's market capitalisation, stands at 371 trillion yuan. There are marked variations in firm size among the Chinese Class A shares. The distribution of the firm size of both Class A shares is significantly skewed to the left, with a fatter tail and higher global maximum point. This pattern of the distribution is consistent across four other proxy variables - firm age, return volatility, trading volume, and quality of corporate governance. In terms of firm age (measured by the number of days the stocks have been listed on the SHSE/SZSE), Share A stocks have been listed for 1478 days on average. Turning now to return volatility (measured by the standard deviation of monthly market excess returns over the year ending at the end of month $t$ ), the Share A stocks had

\footnotetext{
13 Dividends were reinvested automatically.

14 The data of the difference in analysts' earnings forecasts (EPS) are only available from January 2000.

15 Yuan is the base unit of Chinese currency and the primary unit of the reminbi.

16 Free-float ratio is computed by taking the ratio of the number of shares in a listed firm that the firm is free to trade among investors and the total number of shares issued by a company.
} 
Table 1 Descriptive statistics of information uncertainty proxy factors. Source: Wind financial database

\begin{tabular}{llllll}
\hline Proxy factors & Mean & Variance & Skewness & Kurtosis & Jarque-Bera \\
\hline Firm size & $\begin{array}{c}371 \text { (trillion } \\
\text { yuan) }\end{array}$ & $2,746,633,258$ & $1.1573(\mathrm{a})$ & $-0.4447(\mathrm{a})$ & $519.3681(\mathrm{a})$ \\
$\begin{array}{c}1478 \text { days } \\
\text { Firm age }\end{array}$ & 153,290 & $0.3985(\mathrm{a})$ & $-0.6944(\mathrm{a})$ & $1251.284(\mathrm{a})$ \\
$\begin{array}{c}\text { Return } \\
\text { volatility }\end{array}$ & 0.2558 & 2.031 & $0.2185(\mathrm{a})$ & $-0.8153(\mathrm{a})$ & $121.638(\mathrm{a})$ \\
$\begin{array}{c}\text { Trading } \\
\text { volume }\end{array}$ & 37,253 & $5,910,014$ & $1.7235(\mathrm{a})$ & $1.4152(\mathrm{a})$ & $1012.301(\mathrm{a})$ \\
$\begin{array}{c}\text { Analyst } \\
\text { coverage }\end{array}$ & 6.4496 & 5.1832 & $0.5521(\mathrm{a})$ & $-1.3718(\mathrm{a})$ & $159.932(\mathrm{a})$ \\
$\begin{array}{c}\text { Corporate } \\
\text { governance }\end{array}$ & 0.4581 & 0.0058 & $4.2241(\mathrm{a})$ & $15.5624(\mathrm{a})$ & $258.39(\mathrm{a})$ \\
$\begin{array}{c}\text { Difference in } \\
\text { analysts' } \\
\text { opinion }\end{array}$ & 0.0672 & 0.0016 & $-0.2674(\mathrm{a})$ & 1.1018 & $185.571(\mathrm{a})$ \\
\hline
\end{tabular}

been, on average, fairly volatile (0.2558). On the trading volume (measured by turnover ratio) front, Share A stocks, on average, changed hands as frequently as 37,253 times.

For analyst coverage (estimated by the number of analysts following the firm in the previous year), the average number of analysts covering a specific Share A stock is six, falling in the range between one and seven for the sample dataset.

Table 2 shows the correlations between the seven different information uncertainty proxy factors as measured by Pearson correlation (above the diagonal) and Spearman correlation (below the diagonal). Firm size, firm age, and analysts' coverage are positively correlated with each other as expected. ${ }^{17}$ Given the fairly strong correlations between analysts' coverage and firm size $($ Pearson $=0.452$; Spearman $=0.602) /$ firm age $($ Pearson $=0.462$; Spearman $=0.425)$, the measurement of analysts' coverage is carefully calibrated (by adopting a residual analyst's coverage) as detailed in the methodology section below to capture unique characteristics of the information uncertainty proxy. In contrast, the firm size, firm age, and analysts' coverage are negatively correlated with return volatility, indicating the extra volatility associated with smallcap stocks of relatively young firms with deficient analysts' coverage. Quite noticeably, the dispersion in analysts' coverage has very weak correlation with firm size, firm age, analysts' coverage, and return volatility, asserting the importance of including the variable as part of the information uncertainty proxy. However, the dispersion in analysts' coverage is highly correlated with trading volume and strength/quality of corporate governance, reflecting the fact that more frequently traded stocks tend to be associated with better governed firms with more divided opinions among analysts. Moreover, the strength/quality of corporate governance is moderately negatively correlated with firm size, firm age, return volatility, and dispersion in analysts' forecasts and weakly negatively correlated with trading volume (Pearson $=-0.217$; Spear-

$\overline{17}$ This is also consistent with US evidence documented by Jiang et al. (2005) and Zhang (2006). 
Table 2 Correlation matrix

\begin{tabular}{llllllll}
\hline & Size & Age & Cov & Volatility & DISP & Volume & CG \\
\hline \multicolumn{7}{l}{ Pearson correlations are shown above the diagonal } & with Spearman below \\
Size & 1 & 0.346 & 0.452 & -0.294 & -0.248 & -0.267 & -0.285 \\
Age & 0.381 & 1 & 0.462 & -0.352 & 0.058 & -0.169 & -0.301 \\
Cov & 0.602 & 0.425 & 1 & -0.354 & 0.036 & -0.225 & -0.461 \\
Volatility & -0.305 & -0.401 & -0.313 & 1 & 0.025 & 0.387 & -0.228 \\
DISP & -0.264 & 0.063 & 0.051 & 0.039 & 1 & 0.295 & 0.185 \\
Volume & -0.218 & -0.174 & -0.268 & 0.534 & 0.381 & 1 & -0.217 \\
CG & -0.381 & -0.357 & -0.352 & -0.283 & 0.394 & -0.195 & 1 \\
\hline
\end{tabular}

Pearson correlation coefficients are shown above the diagonal; Spearman correlation coefficients are shown below the diagonal. All correlation coefficients are significant at the $1 \%$ level

man $=-0.195)$. It is worth mentioning that the strength of corporate governance factor is strongly negatively correlated with analysts' coverage (Pearson $=-0.461$; Spearman $=-0.352$ ) and moderately positively correlated with dispersion in analysts' coverage (Pearson $=0.185$; Spearman $=0.394$ ), suggesting that the stocks of more stringently-governed firms tend to receive less coverage from analysts and spur less divided opinions among analysts.

\subsection{Methodology}

The degree of information uncertainty is gauged by the seven aforementioned proxy factors. Furthermore, we employ an independent two-way sorting method ${ }^{18}$ to quantify the impact of information uncertainty over momentum profits. The mechanism of the independent two-way sorting procedure has been widely adopted in the existing literature (Jiang et al. 2005; Lee and Swaminathan 2000). Specifically, at the beginning of every month over the entire sample period from January 1996 to December 2010, all the eligible Class A share stocks (stocks with price less than US\$1 at the portfolio formation date are excluded from the sample) are ranked independently based on two criteria-information uncertainty proxy factor and the returns over the prior 6 monthsin ascending order. Based on the ranking, the stocks, bearing equal weights, ${ }^{19}$ are subsequently sorted into five quintile momentum portfolios. The quintile portfolio consisting of $20 \%$ of the highest-ranked stocks based on their past 6-month average returns is entitled the "winner" portfolio, whereas the quintile portfolio consisting of $20 \%$ of the lowest-ranked stocks is termed the "loser" portfolio. According to

\footnotetext{
18 Zero-cost strategy is employed for brevity and ease of comparison.

19 The equally-weighted approach is found to not only result in robust results of momentum returns by numerous studies such as Jegadeesh and Titman (1993) and Lee and Swaminathan (2000) but also enables the study to vividly imitate lay people's investing behaviours, normally biased due to the " $1 / \mathrm{n}$ heuristic" postulated by Benartzi and Thaler (2001). The plausibility of the postulate is supported by many empirical studies in psychology (Allison and Messick 1990; Frederick 2002; Rabin 1997; Samuelson and Zeckhauser 1988).
} 
the ranking based on one of seven information uncertainty proxy factors, $20 \%$ of the highest-ranked stocks form "high IU portfolio"; and 20\% of the lowest-ranked stocks form "low IU" portfolio. To measure the interplay of information uncertainty proxy factors and the momentum profits, we form the "winner-high IU" portfolio by taking the intersection of the "winner" portfolio and "high IU" portfolio. Similarly, the intersection of the "loser" portfolio and "low IU" portfolio forms the "loser-low IU" portfolio; the intersection of the "winner" portfolio and "low IU" portfolio forms the "winner-low IU" portfolio; and the intersection of the "loser" portfolio and "high IU" portfolio forms the "loser-high IU" portfolio. The momentum quintile portfolios are denoted by Q1, Q2, Q3, Q4 and Q5 from the "loser" portfolio to "winner" portfolio, and the IU quintile portfolios IU1, IU2, IU3, IU4, and IU5 from the "low IU" portfolio to "high IU" portfolio. Collectively, there are 25 different portfolios drawn up based on past stock returns and the degree of information uncertainty. All the "IU-momentum" portfolios are held for 6 months after skipping the month subsequent to the end of the 6-month ranking period to avoid provoking microstructure issues ${ }^{20}$ (Galariotis et al. 2007; Jegadeesh 1990; Lehmann 1990). Overlapping portfolios are formed in the process of portfolio-rebalancing to boost the power of the tests (Jegadeesh and Titman 1993). Additionally, a buy-and-hold strategy ${ }^{21}$ is employed to minimise transaction costs. The momentum return ${ }^{22}\left(R_{W-L}\right)$ t different information uncertainty levels is determined by taking the difference of the average monthly return from relevant "winner-IU portfolio" $\left(R_{W}\right)$ d that from the corresponding "loser-IU" portfolio $\left(R_{L}\right)$.

\subsection{UP and DOWN Market States}

Cooper et al.'s (2004) method is implemented ${ }^{23}$ to examine the impact of market fluctuations over the momentum profits at different IU levels. Currently, there is no consensus view on the optimal measurement of market states in the existing literature; however, some results show that macroeconomic factors such as lagged industrial production growth (Huang 2006), a combination of macro variables (Cooper et al. 2004; Du et al. 2009), and the previous 36-month average market return (Cooper et al. 2004; Huang 2006) is ineffective in distinguishing different market states. In view of this, the 12-month average market return is chosen as the main barometer to identify

\footnotetext{
20 To mitigate the potential issues induced by "bid-ask bounce" bias and return serial correlation (Arena et al. 2008) and to avoid "test statistics based on overlapping returns" (Moskowitz and Grinblatt 1999: 1258), a month is skipped between the end of the ranking period and the start of the holding period (Galariotis et al. 2007; Jegadeesh and Titman 1993; Lehmann 1990; McKnight and Hou 2006).

21 The monthly rebalancing strategy used by Jegadeesh and Titman (1993) is not used in this study in order to avoid the incurring of excessive trading costs (for a Class A share transaction, an investor is obliged to pay $0.3 \%$ of trading value as commission to securities firms and $0.1 \%$ of trading value as transfer fee to the Depository \& Clearing Company. In addition, a sell-side investor is also required to pay $0.1 \%$ of trading value as stamp duty to the tax authorities).

22 Mathematically, it can be written as $R_{W-L}=R_{W}-R_{L}$.

23 The method was also adopted by Du et al. (2009), Huang (2006), and Siganos and Chelley-Steeley (2006).
} 
the state of the stock market. ${ }^{24}$ Specifically, the return of a self-constructed market value-weighted share A composite index entailing all the Class A shares listed on the SHSE and SZSE is used to proxy for the average market return of all Class A shares. Two main methodological steps are implemented:

Step 1: the momentum returns conditional on post-UP and-DOWN market states are quantified by regressing the unconditional momentum returns on an UP state dummy and a DOWN state dummy. Mathematically, it can be expressed as

$$
R_{W-L, t}=R_{W-L, U P} U P_{t}+R_{W-L, D O W N} D O W N_{t}+e_{t}
$$

where $R_{W-L, t}$ denotes the momentum profits from different momentum trading strategies; $U P_{t}$ s equal to 1 if it is a UP market state (average market return for the previous 12 or 24 months is positive: $R_{\text {market }, t-1, t-k}>0$ where $\mathrm{k}=12$ or 24 ) and is 0 otherwise; $D O W N_{t}$ s equal to 1 if it is a DOWN market state (average market return for the previous 12 or 24 months is negative: $R_{\text {market }, t-1, t-k}<0$ where $\mathrm{k}=12$ or 24 ) and is zero otherwise. The average momentum return following the UP market state is denoted by $R_{W-L, U P}$ and the average momentum return following the DOWN market state is symbolised by $R_{W-L, D O W N}$.

Step 2: The difference of momentum returns conditional on post-UP and -DOWN market states is determined by regressing the unconditional momentum returns on a UP market state dummy factor. Mathematically, it can be shown as

$$
R_{W-L, t}=\alpha+R_{W-L, U P-D O W N} U P_{t}+e_{t}
$$

where $R_{W-L, U P-D O W N}$ represents the difference of momentum return conditional on two different market states (Du et al. 2009).

\section{Empirical Results}

\subsection{Information Uncertainty and the Momentum Profits}

This study set out to test how firm-level information uncertainty, as measured by the above-listed seven proxy factors, impacts the momentum profits. Chinese Class B shares are excluded from the test due to liquidity and microstructure concerns. As shown in Table 3, we observe a positive relationship between the momentum profits (measured by the difference between average monthly returns of "winner" momentum quintiles and those of "loser" momentum quintiles-Q5-Q1) and the degree of firm-level information uncertainty across different information uncertainty proxy factors. This suggests a general amplifying effect of firm-level information uncertainty over the momentum profits, consistent with what proposition 1 implies. The finding is corroborated by a multitude of behavioural theories and experimental evidence in psychology: under the framework of heuristics and biases tradition, "people

\footnotetext{
24 A 24-month average market return is used as an additional market state definition, reassuring the robustness of the results. These results are available on request.
} 
also appear to be more optimistically biased under conditions of greater uncertainty" (Armor and Taylor 1998; Gilovich et al. 2005). In buoyant mood, spurred by the optimism/confidence sentiment, investors are more inclined to practice a "top-down, heuristics strategy of information processing" on the premise of "preexisting general knowledge structure" (Schwarz 1990: 542) in the judgmental process. During the procedure, investors frequently implement intuitive heuristics such as affective, and prototype heuristics of System 1 (intuitive) of two cognitive systems (Kahneman and Frederick 2002), subsequently eliciting the behavioural biases such as overconfidence, conservatism, under-confidence and under-reaction that are nominated as the impetus behind the momentum profits (Barberis et al. 1998; Daniel et al. 1998; Du 2002; Hong and Stein 1999) in the literature. Following this logic, as the salience of information uncertainty heightens, the momentum profits are expected to get propped up gradually, which is line with the propositions of our hypotheses. ${ }^{25}$

With firm size as the proxy for firm-level information uncertainty, the results ${ }^{26}$ show a negative association between firm-level information uncertainty and the average monthly returns of "loser" portfolios (Q1), indicated by a statistically significant difference of $-0.50(-1.99)$. Similarly, firm-level information uncertainty also proves to accentuate the average monthly returns of "winner" portfolios (Q5) (2.15 with t stat 4.53). In comparison, the average monthly returns of "winner" portfolios are more sensitive to an increasingly elevated firm-level information uncertainty, consistent with the pattern described in Hong, Lim and Stein's (2000) study.

Across seven different information uncertainty proxy factors, ${ }^{27}$ the general pattern-the negative relation between IU and the returns of "loser" momentum quintiles, and the positive relation between IU and the returns of "winner" momentum quintiles - is present and consistent with empirical evidence found by Zhang (2006). This finding corroborates the prediction reliant on investors' under-reaction theory and gradual information diffusion theory developed by Hong and Stein (1999) and Hong et al. (2000) respectively.

The empirical evidence on the impact of firm-level information uncertainty (as measured by the strength of corporate governance) over the momentum profit is presented in Table 4. In the "Q1" ("loser" portfolio) column, there is statistically significant evidence ( -0.28 t-stats: -1.99$)$ implying that the returns of "loser" portfolios deteriorated as the degree of firm-level information uncertainty heightened. This result corroborates the postulate that "weak shareholder rights caused poor performance" of firm shares (Gompers et al. 2003:145). Specifically, weak shareholders' rights, reflected by limited communication between the firm and its shareholders, accentuate the sluggish information diffusion. Subsequently, this leads to a further loss in the

\footnotetext{
25 From a different angle, following the spirit of feelings-as-information theoretical framework, as noted earlier, investors can be rather optimistic under the influence of greater information uncertainty (Armor and Taylor 1998) and the fact that the vast amount of Chinese domestic retail investors' lack of statistical knowledge to override the intuitive heuristics such as affective heuristics (Nisbett et al. 1983), work jointly to give rise to more frequent practice of evaluative judgments (heuristics strategy of information processing) (Schwarz 1990) reflected by the increasingly larger momentum profits as the degree of firm-level information uncertainty heightens.

26 Available upon request.

27 Results are available upon request.
} 
Table 3 Information uncertainty and momentum profits

\begin{tabular}{|c|c|c|c|c|c|}
\hline & \multicolumn{5}{|c|}{ Information uncertainty and momentum profits } \\
\hline & IU1 & IU2 & IU3 & IU4 & IU5 \\
\hline $\begin{array}{l}\text { MOM } \\
\quad(\mathrm{Q} 5-\mathrm{Q} 1)\end{array}$ & \multicolumn{5}{|c|}{ The degree of information uncertainty } \\
\hline Size & 1.55 & 1.84 & 2.01 & 2.25 & 2.61 \\
\hline$t$-stats & 4.01 & 3.17 & 5.22 & 8.28 & 9.16 \\
\hline Age & 0.82 & 1.25 & 1.63 & 1.95 & 2.32 \\
\hline$t$-stats & 5.01 & 4.26 & 7.88 & 5.93 & 11.22 \\
\hline $\mathrm{Cov}$ & 1.82 & 2.25 & 2.63 & 2.96 & 3.82 \\
\hline$t$-stats & 3.15 & 5.22 & 6.15 & 8.02 & 12.16 \\
\hline Volatility & 1.02 & 1.36 & 1.55 & 1.93 & 2.61 \\
\hline$t$-stats & 2.55 & 3.01 & 2.99 & 8.63 & 12.52 \\
\hline DISP & 1.36 & 1.65 & 1.73 & 1.77 & 2.08 \\
\hline$t$-stats & 2.01 & 5.05 & 8.27 & 6.03 & 12.72 \\
\hline Volume & 0.82 & 0.95 & 1.48 & 1.83 & 2.66 \\
\hline$t$-stats & 2.52 & 3.99 & 5.05 & 10.11 & 9.16 \\
\hline CG & 2.03 & 2.62 & 2.95 & 3.51 & 4.05 \\
\hline$t$-stats & 3.03 & 4.77 & 8.08 & 10.55 & 13.15 \\
\hline
\end{tabular}

This table reports the average monthly returns of momentum portfolio (the difference between the average monthly returns of "winner" portfolios and "loser" portfolios at different information uncertainty levels) grouped following the independent two-way sorting approach based on past 6-month stock returns and firm size as proxy for information uncertainty levels in all the eligible Class A stocks listed in the Shanghai Stock Exchange and Shenzhen Stock Exchange over the sample period from January 1996 to December 2013. The degree of firm-level information uncertainty is gauged by firm size (Size), firm age (Age), analysts' coverage (COV), return volatility (Volatility), dispersion of analysts' opinions on earnings forecast (DISP), trading volume (Volume), and the strength of corporate governance (CG). The intersection of the momentum portfolios (Q1, Q2, Q3, Q4, Q5) and the information uncertainty (IU) portfolios (IU1, IU2, IU3, IU4, IU5) is taken to construct 25 different portfolios as the result of an independent two-way sorting approach. Beginning from 1 month (to avoid microstructure issues) subsequent to the end of the ranking period of 6 months, the portfolios, following the buy-and-hold strategy to avoid excessive trading costs (Galariotis et al. 2007), are held for 6 months. The momentum profits for momentum portfolios associated with different information uncertainty levels (IU1, IU2, IU3, IU4 and IU5) are calculated by taking the difference of the equal-weighted average returns of "winner" portfolios and those of corresponding "loser" portfolios (Q5-Q1). The significance of the momentum profits is determined by t statistics, shown below each momentum profits, for the difference between the returns of "winner" portfolio and those of "loser" portfolio. A high $t$ statistic indicates high signifiance of the testing result (momentum profits). All the momentum profits are denoted in percentages

returns on high IU "loser" portfolios (Hong et al. 2000). In addition, the results shown in Table 4 suggest that the average monthly returns of "winner" portfolios increase as the degree of firm-level information uncertainty heightens from 2.75 (IU1) to 4.49 (IU5). The difference between these two average returns is 2.02 and is statistically significant (8.04). Columns Q5-Q1 presents the variation of momentum profits under different degrees of firm-level information uncertainty. We observe the evidence of a gradually increasing momentum profits from 2.03 (3.03) at IU1 to 4.05 (13.15) at IU5, implying the amplifying effect of firm-level information uncertainty upon the 
Table 4 Momentum profits under the impact of firm-level information uncertainty as measured by the strength of corporate governance ( $1 /$ free float ratio)

\begin{tabular}{|c|c|c|c|c|c|c|c|}
\hline & \multicolumn{7}{|c|}{ Momentum Quintile } \\
\hline & Q1 & Q2 & Q3 & Q4 & Q5 & Q5-Q1 & $\mathrm{t}$-value \\
\hline \multicolumn{8}{|c|}{ Corporate governance (proxied by $1 /$ free float ratio) } \\
\hline IU1 & 0.72 & 1.26 & 1.84 & 2.31 & 2.75 & 2.03 & 3.03 \\
\hline$t$-stats & 1.85 & 4.88 & 5.26 & 6.15 & 8.06 & & \\
\hline IU2 & 0.62 & 1.16 & 1.73 & 2.48 & 3.24 & 2.62 & 4.77 \\
\hline t-stats & 1.55 & 3.54 & 5.61 & 7.22 & 8.05 & & \\
\hline IU3 & 0.57 & 0.82 & 1.53 & 2.16 & 3.52 & 2.95 & 8.08 \\
\hline t-stats & 2.05 & 3.55 & 4.17 & 6.22 & 6.08 & & \\
\hline IU4 & 0.45 & 1.15 & 1.69 & 2.05 & 3.96 & 3.51 & 10.55 \\
\hline$t$-stats & 1.05 & 2.99 & 5.05 & 7.26 & 8.15 & & \\
\hline IU5 & 0.44 & 0.75 & 1.28 & 1.87 & 4.49 & 4.05 & 13.15 \\
\hline$t$-stats & 1.52 & 2.99 & 6.01 & 7.22 & 11.26 & & \\
\hline IU5-IU1 & -0.28 & -0.51 & -0.56 & -0.44 & 1.74 & 2.02 & \\
\hline$t$-value & -1.99 & -1.58 & -2.01 & -1.95 & 7.04 & 8.04 & \\
\hline
\end{tabular}

This table reports the average monthly returns of momentum portfolio (the difference between the average monthly returns of "winner" portfolios and "loser" portfolios at different information uncertainty levels) grouped following the independent two-way sorting approach based on past 6-month stock returns and the strength of corporate governance as proxy for information uncertainty levels in the consolidated Class A share market consisting of all the eligible Class A stocks listed in the Shanghai Stock Exchange and Shenzhen Stock Exchange over the sample period from January 1996 to December 2013. The significance of the momentum profits is determined by $t$ statistics, shown below each momentum profits, for the difference between the returns of "winner" portfolio and those of "loser" portfolio. A high $t$ statistic indicates high signifiance of the testing result (momentum profits), All the momentum profits are denoted in percentages

momentum profits. In the face of greater degree of firm-level information uncertainty, investors are prone to be overly optimistic, which triggers the more frequent use of intuitive heuristics such as affective heuristics of the system 1 (intuitive) of two cognitive systems (Kahneman and Frederick 2002). The heuristics processing procedure in the human judgment process is susceptible to the influence of different forms of behavioural bias such as overconfidence and conservatism, which are found to drive the momentum effect (Barberis et al. 1998; Daniel et al. 1998).

\subsection{Information Uncertainty and the Price Momentum Phenomenon Amidst Market Swings}

In view of the empirical evidence documenting the impact of market dynamics upon the momentum profits (Cooper et al. 2004; Du et al. 2009; Huang 2006), we investigate the dynamics of the market-state-dependent momentum profits at different levels of firm-level information uncertainty in the Chinese stock market. In addition, this study contributes to the debate on the interaction between the momentum profits and information uncertainty by interpreting the empirical results under the aegis of heuristics 
and bias traditions (Tversky and Kahneman 1974) and behavioural finance theories. The market states are defined by the prior 12/24-month average monthly return of a consolidated Chinese Share A index.

As shown in Table 5, we find evidence unanimously showing that the IU-( $R=6$, $\mathrm{H}=6$ ) momentum profits conditional on post-DOWN market state outstrip those conditional on post-UP market state across seven different firm-level IU proxy factors, which is consistent with proposition 2. In short, under Kahneman and Frederick's (2002) two cognitive system theoretical frameworks, the limited availability of investors' cognitive resources elicits frequent use of intuitive heuristics (Schwarz 1990), which leads to a more prevalent momentum effect. This knock-on effect of this mechanism is further accentuated when investors are facing higher degrees of firm-level information uncertainty.

Specifically, when firm size (measured by its market capitalisation) is used to gauge different degrees of firm-level information uncertainty, what the results imply is twofold: (1) a consistent pattern indicates that momentum profits gradually increase as firm-level information uncertainty heightens from 1.15 to $2.14 \%$ for post-UP market condition and from 1.42 to $2.53 \%$ for post-DOWN market condition, and (2) the momentum profits found conditional on post-DOWN market state outstrip those found conditional on post-UP market state across different degrees of firm-level information uncertainty. This finding lends support to the crux of Hong et al.'s (2000) gradual information diffusion theory, implying that the momentum effect is accentuated by the sluggish scattering of news concerning small-sized firms associated with higher degrees of firm-level information uncertainty.

Furthermore, the results from the equality test reaffirm the superior momentum profits conditional on IU and post-DOWN market state across different degrees of firm-level information uncertainty. As presented in Table 6, the momentum profits conditional on post-DOWN market state eclipses those conditional on post-UP market state by an average of 0.28 ; this is highly statistically significant. This pattern is also unanimous across different degrees of firm-level information uncertainty. Aided by Du's (2002) investors' under-confidence model, we propose that with the market slides in their rear-view mirror, the vast amount of Chinese retail investors (Kang et al. 2002) are prone to carry the dim view that they hold of the market further (Brown and Cliff 2004; Fisher and Statman 2002). This lingering bearish view, along with a higher degree of firm-level information uncertainty, accentuates the momentum profits. In contrast, riding the wave of the optimistic sentiment following market run-ups, investors have more cognitive resources (Armor and Taylor 1998) and are inclined to process information using systematic heuristics such as neural, statistical, and abstract heuristics. ${ }^{28}$ This mechanism improves the efficiency of information diffusion and deters the influence of investors' under-confidence, consequently depressing the momentum profits.

The results using the other six variables as firm-level information uncertainty generally resemble what is observed when firm size is used to gauge the firm-level information uncertainty.

\footnotetext{
28 Systematic heuristics are used in the System 2 (reflective system) of the two cognitive systems (Kahneman and Frederick 2002) in the information-processing procedure.
} 
Table 5 Firm-level information uncertainty and momentum profits amidst UP and DOWN market states (prior-12 month average market return) in the Chinese Class A share market (January 1996-December 2013)

\begin{tabular}{lllccc}
\hline Q5-Q1 & $\begin{array}{l}\text { IU1 } \\
\text { Degree of firm-level information uncertainty }\end{array}$ & IU5-IU1 \\
\hline
\end{tabular}

Firm-level information uncertainty and momentum profits

Prior 12-month market average return

\begin{tabular}{|c|c|c|c|c|c|c|}
\hline Size (UP) & 1.15 & 1.53 & 1.86 & 2.05 & 2.14 & 0.99 \\
\hline$t$-stats & 2.55 & 3.01 & 2.66 & 3.82 & 6.25 & 2.11 \\
\hline Size (DOWN) & 1.42 & 1.86 & 2.08 & 2.24 & 2.53 & 1.11 \\
\hline$t$-stats & 4.66 & 8.25 & 10.55 & 13.99 & 10.55 & 3.55 \\
\hline Age (UP) & 0.54 & 0.68 & 0.85 & 1.14 & 1.42 & 0.88 \\
\hline t-stats & 1.99 & 2.05 & 3.05 & 3.99 & 5.05 & 4.04 \\
\hline Age (DOWN) & 0.64 & 0.83 & 1.42 & 2.42 & 2.81 & 2.17 \\
\hline t-stats & 3.99 & 6.15 & 8.55 & 8.44 & 10.04 & 5.05 \\
\hline COV(UP) & 1.86 & 2.13 & 2.36 & 2.51 & 2.72 & 0.86 \\
\hline t-stats & 2.99 & 5.05 & 3.77 & 5.44 & 6.04 & 4.08 \\
\hline COV(DOWN) & 2.51 & 2.84 & 3.82 & 4.16 & 4.37 & 1.86 \\
\hline t-stats & 3.06 & 5.05 & 6.04 & 8.99 & 9.06 & 8.33 \\
\hline Volatility (UP) & 0.38 & 0.52 & 0.84 & 1.02 & 1.56 & 1.18 \\
\hline t-stats & 1.99 & 3.01 & 3.88 & 4.05 & 6.03 & 2.99 \\
\hline Volatility (DOWN) & 1.14 & 1.75 & 2.16 & 2.42 & 2.94 & 1.8 \\
\hline t-stats & 3.82 & 6.99 & 8.55 & 11.52 & 9.55 & 4.69 \\
\hline DISP (UP) & 0.94 & 1.29 & 1.61 & 1.84 & 2.03 & 1.09 \\
\hline t-stats & 2.99 & 4.05 & 8.55 & 5.73 & 8.05 & 3.64 \\
\hline DISP(DOWN) & 1.26 & 1.75 & 1.85 & 2.04 & 2.28 & 1.02 \\
\hline t-stats & 3.05 & 5.05 & 5.05 & 6.11 & 6.19 & 4.17 \\
\hline Volume (UP) & 0.54 & 0.85 & 1.04 & 1.25 & 1.53 & 0.99 \\
\hline t-stats & 2.05 & 3.99 & 5.05 & 6.33 & 7.99 & 3.15 \\
\hline Volume (DOWN) & 1.53 & 1.74 & 2.04 & 2.53 & 2.88 & 1.35 \\
\hline t-stats & 4.08 & 5.37 & 7.35 & 8.07 & 9.01 & 7.55 \\
\hline CG (UP) & 1.83 & 2.07 & 2.64 & 2.85 & 3.15 & 1.32 \\
\hline t-stats & 4.05 & 6.05 & 7.88 & 4.95 & 6.44 & 4.55 \\
\hline CG (DOWN) & 2.37 & 2.63 & 2.94 & 3.48 & 3.97 & 1.6 \\
\hline t-stats & 3.55 & 6.22 & 7.15 & 7.03 & 8.55 & 7.83 \\
\hline
\end{tabular}

This table presents the momentum returns at different degrees of firm-level IU over the time periods following UP and DOWN market states in the Chinese Class A share market for the sample period from January 1996 to December 2013. The UP and DOWN market states are defined by prior 12-month average market returns, with a consolidated Chinese Share A index being employed as a proxy for market portfolio. The momentum profits (Q5-Q1) are determined by the difference between the average monthly return of the "winner" portfolio (Q5) and that of the "loser" portfolio (Q1), the significance of which is indicated by corresponding $\mathrm{t}$ statistics. A high $t$ statistic indicates high signifiance of the testing result (momentum profits). The calculation of the momentum profits at different degrees of firm-level IU conditional on postUP and DOWN market states is akin to the approach taken by Cooper et al. (2004), Du et al. (2009), Huang (2006) and Siganos and Chelley-Steeley (2006). Mathematically, the procedure can be expressed as $R_{W-L, t}=R_{W-L, U P} U P_{t}+R_{W-L, D O W N} D O W N_{t}+e_{t}$. All the momentum profits in the table are denoted in percentages 
Table 6 Equality test results of the momentum profits conditional on IU and post-UP/DOWN market states (firm size as IU measurement variable)

\begin{tabular}{lcccccc}
\hline & IU1 & IU2 & IU3 & IU4 & IU5 & IU5-IU1 \\
\hline $\begin{array}{l}\text { Equality test (MOM and IU (1/MV)) } \\
\text { Q5-Q1 }\end{array}$ & 1.15 & 1.53 & 1.86 & 2.05 & 2.14 & 0.99 \\
$\begin{array}{l}\text { (UP) } \\
\text { Q5-Q1(DOWN) }\end{array}$ & 1.42 & 1.86 & 2.08 & 2.24 & 2.53 & 1.11 \\
Difference & -0.27 & -0.33 & -0.22 & -0.19 & -0.39 & \\
t stats & -3.05 & -4.82 & -5.88 & -4.27 & -6.15 & \\
\hline
\end{tabular}

This table reports the results from the equality test on the difference between the momentum profits conditional on post-UP and DOWN market states across five different levels of firm-level information uncertainty for Chinese Class A shares from January 1996 to December 2013. The method is similar to that employed by Cooper et al. (2004): $R_{W-L, t}=\alpha+R_{W-L, U P-D O W N} U P_{t}+e_{t}$

In regard to the role of the strength of corporate governance as a measurement of firm-level information uncertainty, the results summarised in Table 7 show the presence of the prevalent amplifying effect of the firm-level information uncertainty over momentum profits. Specifically, when the investigation is set conditional on postUP market state (Panel A of Table 7), the momentum profits (Q5-Q1) creeps up from 1.83 to 3.15 , and the difference between the momentum profits found at IU1 and that found at IU5 is strongly statistically significant (1.32: 4.55). When conditional on the post-DOWN market state (Panel B of Table 7), the momentum profit rises from 2.37 to 3.97 ; both are significant at the $5 \%$ level. Two unanimous patterns can be observed in Panels A and B: 1) the returns of "loser" portfolio (Q1) decrease by 0.49 during post-UP market state and 0.38 during post-DOWN market state as the degree of firm-level information uncertainty heightens, suggesting that firms with lacklustre prior performance and weaker corporate governance tend to underperform; and 2) the return of "winner" portfolio rises as the firm's corporate governance weakens from 1.83 to 3.15 (post-UP market state) and from 2.37 to 3.97 (post-DOWN market state). This indicates that investors are compensated for by keeping stocks associated with higher firm-level information uncertainty.

\section{Robustness Test}

\subsection{Sub-period Analysis}

In the light of the claim that business cycles are attributable to the momentum phenomenon (Antoniou et al. 2007), a sub-period analysis is employed revolving around two of the salient financial reforming events to test the robustness of the results. Specifically, the two events are (1) the implementation of the new PRC security law on 1 July 1999, and (2) the opening of the Chinese Class A share market to qualified foreign institutional investors (QFII) on 9 July 2003. Both these events were found to have ameliorated the operational efficiency of the Chinese stock market as documented by Lin and Swanson (2008). Methodologically, the time periods revolving 
Table 7 Momentum profits and firm-level information uncertainty conditional on post-UP and -DOWN market states (12 months) in the Chinese Class A share market (January 1996-December 2013)

$\begin{array}{lrrrrrr}\text { IU1 } & \text { IU2 } & \text { IU3 } & \text { IU4 } & \text { IU5 } & \text { IU5-IU1 } & \text { t-value } \\ \text { The strength of corporate } & \text { governance } & \text { (residual free } & \text { float ratio) } & & & \end{array}$

Panel A: Momentum profits and firm-level information uncertainty

Post-UP market state condition

$\begin{array}{llllllrr}\text { Q1 } & 1.15(*) & 1.04(*) & 0.95(* *) & 0.74(* *) & 0.66(* *) & -0.49(* *) & -3.95 \\ \text { Q2 } & 1.26(*) & 1.17(*) & 1.14(* *) & 0.87(* *) & 0.74(* *) & -0.52(* *) & -5.11 \\ \text { Q3 } & 1.78(*) & 1.55(*) & 1.52(* *) & 1.49(* *) & 1.39(* *) & -0.39(* *) & -6.13 \\ \text { Q4 } & 2.37(* *) & 2.09(* *) & 2.02(* *) & 1.83(* *) & 1.72(* *) & -0.65(* *) & -5.51 \\ \text { Q5 } & 2.98(* *) & 3.11(* *) & 3.59(* *) & 3.59(* *) & 3.81(* *) & 0.83(* *) & 4.05 \\ \text { Q5-Q1 } & 1.83(* *) & 2.07(* *) & 2.64(* *) & 2.85(* *) & 3.15(* *) & 1.32(* *) & 4.55\end{array}$

Panel B: Momentum profits and firm-level information uncertainty

Post-DOWN market state condition

\begin{tabular}{lllllllr} 
Q1 & $1.13(* *)$ & $1.05(* *)$ & $0.92(* *)$ & $0.83(*)$ & $0.75(* *)$ & $-0.38(* *)$ & -4.05 \\
Q2 & $1.29(* *)$ & $1.16(* *)$ & $1.04(* *)$ & $0.96(* *)$ & $0.92(*)$ & $-0.37(* *)$ & -3.99 \\
Q3 & $1.71(* *)$ & $1.58(* *)$ & $1.33(* *)$ & $1.29(* *)$ & $1.17(* *)$ & $-0.54(* *)$ & -6.02 \\
Q4 & $2.07(* *)$ & $1.94(* *)$ & $1.88(* *)$ & $1.71(* *)$ & $1.62(* *)$ & $-0.45(* *)$ & -3.11 \\
Q5 & $3.5(* *)$ & $3.68(* *)$ & $3.86(* *)$ & $4.31(* *)$ & $4.72(* *)$ & $1.22(* *)$ & 4.52 \\
Q5-Q1 & $2.37(* *)$ & $2.63(* *)$ & $2.94(* *)$ & $3.48(* *)$ & $3.97(* *)$ & $1.6(* *)$ & 7.83 \\
t-value & 3.55 & 6.22 & 7.04 & 7.03 & 8.55 & \\
\hline
\end{tabular}

This table presents the average monthly returns of momentum quintiles conditional on different degrees of firm-level IU and post-UP and post-DOWN market states (in Panel A and Panel B respectively) in the Chinese Class A share market for the sample period spanning from January 1996 to December 2013. The UP and DOWN market states are defined by prior 12-month average market return, with a consolidated Chinese Share A index being employed as a proxy for market portfolio. The portfolios are formed based on the independent two-way sorting mechanism. All the eligible stocks are ranked based on their prior 6-month returns and the corporate governance proxy - free float ratio, measured by the ratio of the number of shares in a listed firm freely to be traded among all the investors and total number of shares of the firm, independently into five quintiles for each factor. Taking the intersections of these 10 quintiles gives rise to 25 momentum-IU portfolios in total, with every stock being equally weighted within every portfolio. After skipping a month, all the resulting portfolios are held for 6 months following the buy-and-hold strategy to curb trading costs from the perspective of practicality. The momentum profits (Q5-Q1) is determined by the difference between the average monthly return of "winner" portfolio (Q5) and that of "loser" portfolio (Q1), the significance of which is indicated by corresponding t statistics. A high t statistic indicates high signifiance of the testing result (momentum profits). The calculation of the momentum profits under influence of IU over the periods following UP and DOWN market states is akin to the approach taken by Cooper et al. (2004), Du et al. (2009), Huang (2006) and Siganos and Chelley-Steeley (2006). Mathematically, the procedure can be expressed as $R_{W-L, t}=R_{W-L, U P} U P_{t}+R_{W-L, D O W N} D O W N_{t}+e_{t}$. All the momentum profits in the table are denoted in percentages. $*$ indicates a $10 \%$ statistical significance level and ** indicates a $5 \%$ statistical significance level

around the two salient financial market regulatory reforms are split into pre-event periods and post-event periods - for the implementation of the new PRC securities law (1 July 1999): pre-event period (January 1998-June 1999) and post-event period (August 1999-January 2001); for the opening of Chinese Class A share market to qualified for- 
eign institutional investors (QFII) (9 July 2003): pre-event period (January 2002-June 2003) and post-event period (August 2003-January 2005).

During pre-event time periods, jittery over the uncertainty revolving around the implementation of new regulatory reforms, investors heighten their perception of risk (Schwarz 1990), which accentuates the impact of the sluggish information diffusion. This surmises with our expectation of more prevalent momentum profits during preevent time periods (Hong et al. 2000). In contrast, during post-event time periods, if the launch of a regulatory reform receives a warm reception, the optimistic sentiment would free up investors' cognitive resources. The more generous availability of investors' cognitive resources elicits the practice of reflective heuristics such as statistical heuristics in System 2 (systematic) of Kahneman and Frederick's (2002) two cognitive systems. Therefore, we are expecting slightly weaker momentum profits during post-event periods. From the perspective of operational efficiency of the market, a weaker momentum profits expected in the post-event period would suggest an improvement in the operational efficiency (Pena 1995), in line with the aim of the two Chinese stock market regulatory reforms (Lin and Swanson 2008).

We run the sub-period analysis test to examine the resilience of the momentum profits conditional on different degrees of firm-level information uncertainty and find consistent results across seven different firm-level information uncertainty proxies. Table 8 reports the conditional momentum profits on the firm-level information uncertainty (measured by firm size ${ }^{29}$ ) during the launch of the two salient market regulatory reforms - the implementation of the new PRC security law and the opening of the Chinese Class A share market to qualified foreign institutional investors (QFII). Across the board, the conditional momentum profits are all positive and statistically significant. During all four sub-sample periods, the momentum profit tends to rise as firm-level information uncertainty heightens. This result indicates that the amplifying of firm-level information uncertainty upon the momentum profit persists. In addition, the conditional momentum profits found during pre-event time periods tends to outpace that found during post-even time periods for both regulatory reforms, which is largely in line with our expectations. In short, this result suggests that investors frequently practice reflective heuristics in their decision-making process (Kahneman and Frederick 2002) during post-event time periods or an improvement in the operational efficiency of the Chinese stock market.

\subsection{Risk Adjustment by Two Versions of the FF3F Models ${ }^{30}$}

We further test the resilience of the conditional momentum profits based on two versions of the Fama and French three-factor (FF3F hereafter) model (Fama and French 1993). Specifically, the original version of the FF3F incorporates a market-risk factor $\left(R_{m, t}-R_{f, t}\right)$ a firm-size effect factor $\left(S M B_{t}\right)$ nd a value-effect factor ${ }^{31}\left(H M L_{t}\right)$ In line

\footnotetext{
29 The rest of the results are available upon request.

30 The rest of risk-adjustment results are available upon request.

31 The question of whether firm size-effect factor and value-effect factor should be categorised as risk factors remains debatable (Ferson and Harvey 1999) in the literature.
} 
Table 8 Momentum profits and firm-level information uncertainty-a sub-period analysis (Firm size as the measurement of firm-level information uncertainty)

Firm-level information uncertainty and momentum profits

Firm size as firm-level IU measurement

\begin{tabular}{|c|c|c|c|c|c|}
\hline \multirow[b]{2}{*}{ Time period } & \multicolumn{5}{|c|}{ Degree of firm-level information uncertainty } \\
\hline & IU1 & IU2 & IU3 & IU4 & IU5 \\
\hline $\begin{array}{l}\text { Jan. 1996-Dec. } \\
2013\end{array}$ & $1.55(* *)$ & $1.84(* *)$ & $2.01(* *)$ & $2.25(* *)$ & $2.61(* *)$ \\
\hline Event 1 & \multicolumn{5}{|c|}{ The implementation of the P.R.C. security law } \\
\hline $\begin{array}{l}\text { Pre-event(Jan. } \\
\text { 1998-July } \\
\text { 1999) }\end{array}$ & $1.56(* *)$ & $1.85(* *)$ & $1.93(* *)$ & $2.18(* *)$ & $2.53(* *)$ \\
\hline $\begin{array}{l}\text { Post-event } \\
\text { (Aug. } \\
\text { 1999-Jan. } \\
\text { 2001) }\end{array}$ & $1.14(* *)$ & $1.35(* *)$ & $1.4(* *)$ & $1.52(* *)$ & $1.75(* *)$ \\
\hline Event 2 & \multicolumn{5}{|c|}{ Openings to qualified foreign institutional investors (QFII) } \\
\hline $\begin{array}{l}\text { Pre-event (Jan. } \\
\text { 2002-July } \\
\text { 2003) }\end{array}$ & $1.48(* *)$ & $1.82(* *)$ & $1.93(* *)$ & $2.05(* *)$ & $2.61(* *)$ \\
\hline $\begin{array}{l}\text { Post-event } \\
\text { (Aug. } \\
\text { 2003-Jan. } \\
\text { 2005) }\end{array}$ & $1.32(* *)$ & $1.69(* *)$ & $1.75(* *)$ & $1.89(* *)$ & $2.31(* *)$ \\
\hline
\end{tabular}

This table reports the momentum profits conditional on different degrees of firm-level information uncertainty over pre-event and post-event periods revolving around two salient Chinese stock market reforms-1) the launch of the PRC security law in July 1999, and 2) the openings of Class A shares to qualified foreign institutional investors (QFII) in the Chinese Class A share market. * indicates statistical significance at the $10 \%$ significance level; ** indicates statistical significance at the 5\% significance level. All the momentum profits are denoted in percentages

with Wang and Xu's (2004) approach, the conditional momentum profit is also adjusted against a unique set of risk factors-a market-risk factor $\left(R_{m, t}-R_{f, t}\right)$ a firm-size effect factor $\left(S M B_{t}\right)$ nd a residual free float ratio ${ }^{32}$ (the strength of corporate governance factor) $\left(R F F \_H M L_{t}\right)$ In the setting of the Chinese stock market, supplanting the valueeffect factor with the strength of corporate governance factor is found to improve the explanatory power of the asset-pricing model.

As shown in Table 9, we find that the conditional momentum profits become significantly more subdued both in magnitude and statistical significance. In addition, the results across different firm-level information uncertainty measurements unanimously suggest that Wang and Xu's (2004) version of the FF3F model is superior in justifying the conditional momentum profit. However, neither of these two asset-pricing

\footnotetext{
32 Consistent with Wang and Xu's (2004) approach, the residual free float ratios are estimated by regressing free float ratios against logarithm market capitalisation of corresponding firms at the end of June every year.
} 
Table 9 Risk-adjusted momentum profits and firm-level information uncertainty in the Chinese Class A share market over January 1996 to December 2013 based on two versions of the FF3F model

\begin{tabular}{|c|c|c|c|c|c|c|}
\hline \multirow{2}{*}{$\begin{array}{l}\text { IU measure- } \\
\text { ments }\end{array}$} & \multicolumn{6}{|c|}{ Firm-level IU } \\
\hline & & IU1 & IU2 & IU3 & IU4 & IU5 \\
\hline \multicolumn{7}{|c|}{ Momentum profits and firm-level information uncertainty } \\
\hline \multirow[t]{2}{*}{ Firm size } & FF3F & $1.06(*)$ & 0.82 & $0.86(*)$ & $0.75(*)$ & $0.83(*)$ \\
\hline & WXFF3F & 0.46 & 0.36 & 0.44 & 0.34 & 0.58 \\
\hline \multirow[t]{2}{*}{ Firm age } & FF3F & 0.28 & 0.46 & $0.55(*)$ & $0.58(*)$ & $0.63(*)$ \\
\hline & WXFF3F & 0.15 & 0.21 & 0.27 & 0.36 & 0.39 \\
\hline \multirow[t]{2}{*}{$\mathrm{COV}$} & FF3F & 0.67 & $0.86(*)$ & $1.03(*)$ & $1.01(*)$ & 0.94 \\
\hline & WXFF3F & 0.36 & 0.39 & 0.47 & 0.52 & 0.55 \\
\hline \multirow[t]{2}{*}{ VOL } & FF3F & 0.31 & 0.37 & $0.42(*)$ & 0.41 & $0.53(*)$ \\
\hline & WXFF3F & 0.12 & 0.11 & 0.17 & 0.21 & 0.32 \\
\hline \multirow[t]{2}{*}{ DISP } & FF3F & 0.63 & 0.57 & $0.73(*)$ & $0.82(*)$ & $0.81(*)$ \\
\hline & WXFF3F & 0.31 & 0.35 & 0.46 & 0.29 & 0.46 \\
\hline \multirow[t]{2}{*}{ Volume } & FF3F & 0.31 & 0.35 & 0.3 & 0.41 & $0.53(*)$ \\
\hline & WXFF3F & 0.13 & 0.26 & 0.19 & 0.25 & 0.42 \\
\hline \multirow[t]{2}{*}{ CG } & FF3F & 0.85 & $0.95(*)$ & $1.03(*)$ & $0.96(*)$ & $1.09(*)$ \\
\hline & WXFF3F & 0.36 & 0.51 & 0.74 & 0.82 & 0.79 \\
\hline
\end{tabular}

This table reports the risk-adjusted momentum profits conditional on firm-level information uncertainty in the Chinese Class A share market over January 1996 to December 2013 based on two versions of the FF3F model -the traditional FF3F model: $R_{(W-L), t}-R_{f, t}=\alpha+\beta\left(R_{m . t}-R_{f . t}\right)+s\left(S M B_{t}\right)+h\left(H M L_{t}\right)+e_{t}$ and Wang and Xu's (2004) version of the FF3F model: $R_{(W-L), t}-R_{f, t}=\alpha+\beta\left(R_{m . t}-R_{f . t}\right)+$ $s\left(S M B_{t}\right)+f\left(R F F_{-} H M L_{t}\right)+e_{t}$. * indicates statistical significance at the $10 \%$ level; ** indicates statistical significance at the $5 \%$ level

models is able to fully explain the conditional momentum profit under the influence of firm-level information uncertainty. ${ }^{33}$

\section{Conclusion}

The paper extends the understanding of the momentum phenomenon in the setting of the Chinese stock market by investigating the impact of firm-level information uncertainty over the momentum profits amid market swings.

\footnotetext{
33 To boost the power of our test and underscore the robustness of the findings in this study, we also run the tests to investigate the dynamics of the momentum profits under the influence of IU over time periods following two different market states-UP and DOWN, with the market states defined by prior 24-month market average return, differing from prior 12-month market average return used to defined market states. Overall, the results from the above-mentioned test strikingly resemble the patterns of the results found when prior 12-month is used as the market state definition, corroborating the finding that the amplifying of IU over momentum profits is particularly pronounced over time periods following DOWN market state yet dampened over time periods following UP market state across all IU proxy factors except for the quality of corporate governance (results are available upon request).
} 
By employing seven factors - firm size, firm age, analysts' coverage, return volatility, dispersion in analysts' earnings forecast, trading volume, and the quality/strength of corporate governance (free float ratio) - to proxy for the degree of firm-level information uncertainty (IU), we find that the returns of the "loser" momentum quintile (Q1) tend to be negatively related to firm-level IU, whilst the returns of the "winner" momentum quintile (Q5) are positively associated with firm-level IU. This accords with the predictions of our hypotheses and is corroborated by the under-reaction theory and gradual information diffusion theory (Hong and Stein 1999; Hong et al. 2000). Furthermore, we find that momentum profit increases as the degree of firm-level information uncertainty heightens, indicating the amplifying effect of firm-level information uncertainty upon the momentum profits. This phenomenon can be explained using the theoretical framework of human cognitive bias. In the face of a greater degree of firm-level information uncertainty, market participants are inclined to embrace a more extensive practice of intuitive heuristics such as affective, representativeness heuristics of System 1 (intuitive) of two cognitive systems (Kahneman and Frederick 2002) in their decision-making processes. This mechanism contributes to the amplifying effect of firm-level information uncertainty.

In addition, we also find that the amplifying effect of information uncertainty over the momentum profit is exacerbated over the post-DOWN market states. This phenomenon can be driven by investors' under-confidence and relatively limited availability of cognitive resources in investors' decision-making processes. Specifically, subsequent to market downdrafts, the lingering bearish sentiment coupled with heightened degree of firm-level information uncertainty undermines investors' confidence and the availability of market participants' cognitive resources (Brown and Cliff 2004). This elicits more frequent practice of intuitive heuristics of System 1 of the two cognitive systems in investors' decision-making processes (Kahneman and Frederick 2002), which in turn accentuates the conditional momentum profit.

Through a sub-period analysis revolving the inception of two financial market regulatory reforms - (1) 1 July 1999: the implementation of the new PRC security law; and (2) 9 July 2003: the opening of the Chinese Class A share market to qualified foreign institutional investors (QFII) — we affirm the resilience of the findings. In the risk-adjustment process, we employ two versions of the FF3F asset-pricing models. Results show that neither model can fully explain the conditional momentum profits. However, Wang and Xu's (2004) model - the value-effect factor is replaced by a residual free float ratio-holds superior explanatory power over the conditional momentum profits in the setting of the Chinese Class A share market.

In this line of research, where most prior empirical studies focused on the evidence of the momentum profit or time-varying conditional momentum profit in the setting of the Chinese stock market, our results contribute to the literature by exploring the characteristics of the momentum profits conditional on both market states and firm-level information uncertainty. We particularly explored the unique role of the strength of corporate governance in the setting as a firm-level information uncertainty measurement and a risk factor embedded in Wang and Xu's (2004) FF3F asset-pricing model. To the best of the author's knowledge, this niche field has never been touched upon in previous research. 
Due to its lack of interrelation with other developed financial markets, the Chinese stock market is a prime sourcing location for international investors to achieve portfolio diversification strategies. Therefore, the understanding of the characteristics of the momentum profits conditional on market states and firm-level information uncertainty is important to global investors.

In future studies, the discussion on the reasons why the strength of corporate governance can play such a unique role in the Chinese Class A share market can be further extended.

Open Access This article is distributed under the terms of the Creative Commons Attribution 4.0 International License (http://creativecommons.org/licenses/by/4.0/), which permits unrestricted use, distribution, and reproduction in any medium, provided you give appropriate credit to the original author(s) and the source, provide a link to the Creative Commons license, and indicate if changes were made.

\section{References}

Allison, S. T., \& Messick, D. M. (1990). Social decision heuristics and the use of share resources. Journal of Behavioural Decision Making, 3(3), 195-204.

Amihud, Y., \& Mendelson, H. (1986). Asset pricing and the bid-ask spread. Journal of Financial Economics, 17(2), 223-249.

Antoniou, A., Lam, H. Y. T., \& Paudyal, K. (2007). Profitability of momentum strategies in international markets: The role of business cycle variables and behavioural biases. Journal of Banking \& Finance, 31(3), 955-972.

Arena, M., Haggard, K., \& Yan, X. (2008). Price momentum and idiosyncratic volatility. The Financial Review, 43(2), 159-190.

Armor, D. A., \& Taylor, S. E. (1998). Situated optimism: Specific outcome expectancies and self-regulation. Advances in Experimental Social Psychology, 30, 309-379.

Barberis, N., Shleifer, A., \& Vishny, R. (1998). A model of investor sentiment. Journal of Financial Economics, 49(3), 307-343.

Benartzi, S., \& Thaler, R. H. (2001). Naive diversification strategies in defined contribution saving plans. American Economic Review, 91(1), 79-98.

Bhushan, R. (1989). Firm characteristics and analyst following. Journal of Accounting and Economics, 11(2-3), 255-274.

Brown, G. W., \& Cliff, M. T. (2004). Investor sentiment and the near-term stock market. Journal of Empirical Finance, 11(1), 1-27.

Bushman, R., \& Smith, A. (2001). Financial accounting information and corporate governance. Journal of Accounting and Economics, 32(1-3), 237-333.

Cai, C. X., Keasey, K., \& Short, H. (2006). Corporate governance and information efficiency in security markets. European Financial Management, 12(5), 763-787.

Chan, K. C., \& Chen, N. F. (1991). Structural and return characteristics of small and large firms. The Journal of Finance, 46(4), 1467-1484.

Chui, A. C. W., Titman, S., \& Wei, K. C. J. (2010). Individualism and momentum around the world. The Journal of Finance, 65(1), 361-392.

Cooper, M., Gutierrez, R., \& Hameed, A. (2004). Market states and momentum. The Journal of Finance, 59(3), 1345-1365.

Daniel, K., Hirshleifer, D., \& Subrahmanyam, A. (1998). Investor psychology and security market underand overreactions. The Journal of Finance, 53(6), 1839-1885.

Diether, K., Malloy, C., \& Scherbina, A. (2002). Differences of opinion and the cross section of stock returns. The Journal of Finance, 57(5), 2113-2141.

Dische, A. (2002). Dispersion in analyst forecasts and the profitability of earnings momentum strategies. European Financial Management, 8(2), 211-228.

Drobetz, W., Schillhofer, A., \& Zimmermann, H. (2004). Corporate governance and expected stock returns: Evidence from Germany. European Financial Management, 10(2), 267-293. 
Du, J. (2002). Heterogeneity in investor confidence and asset market under-and overreaction. The SSRN. http://papers.ssrn.com/sol3/papers.cfm?abstract_id=302684. Accessed Feb 09, 2016.

Du, D., Huang, Z., \& Liao, B. (2009). Why is there no momentum in the Taiwan stock market? Journal of Economics and Business, 61(2), 140-152.

Fama, E. (1965). The behavior of stock-market prices. The Journal of Business, 38(1), 34-105.

Fama, E., \& French, K. (1993). Common risk factors in the returns on stocks and bonds. Journal of Financial Economics, 33(1), 3-56.

Ferson, W. E., \& Harvey, C. R. (1999). Conditioning variables and the cross section of stock returns. The Journal of Finance, 54(4), 1325-1360.

Fisher, K., \& Statman, M. (2000). Investor sentiment and stock returns. Financial Analysts Journal, 56(2), $16-23$.

Fisher, K. L., \& Statman, M. (2002). Blowing bubbles. The Journal of Psychology and Financial Markets, 3(1), 53-65.

Frederick, S. (2002). Automated choice heuristics. In T. Gilovich, D. Griffin (Eds.), Heuristics and biases: The psychology of intuitive judgment (pp. 548-558). New York: Cambridge University Press.

Galariotis, E. C., Holmes, P., \& Ma, X. S. (2007). Contrarian and momentum profitability revisited: Evidence from the London Stock Exchange 1964-2005. Journal of Multinational Financial Management, 17(5), $432-447$.

Gillan, S., Hartzell, J., \& Starks, L. (2006). Tradeoffs in corporate governance: Evidence from board structures and charter provisions. Quarterly Journal of Finance, 1(4), 667-705.

Gilovich, T. (1993). How we know what isn't so: The fallibility of human reason in everyday life. New York: The Free Press.

Gilovich, T., Griffin, D. W., \& Kahneman, D. (2005). Heuristics and biases: The psychology of intuitive judgement. Cambridge: Cambridge University Press.

Gompers, P., Ishii, J., \& Metrick, A. (2003). Corporate governance and equity prices. Quarterly Journal of Economics, 118(1), 107-155.

Graham, B., \& Zweig, J. (2003). The intelligent investor. New York: Harper Business.

Griffin, D., \& Tversky, A. (1992). The weighing of evidence and the determinants of confidence. In T. Gilovich, D. Griffin (Eds.), Heuristics and biases-The psychology of intuitive judgment (pp. 230-249). New York: Cambridge University Press.

Grinblatt, M., Titman, S., \& Wermers, R. (1995). Momentum investment strategies, portfolio performance, and herding: A study of mutual fund behavior. American Economic Review, 85(5), 1088-1105.

Hong, H., Lim, T., \& Stein, J. (2000). Bad news travels slowly: Size, analyst coverage, and the profitability of momentum strategies. The Journal of Finance, 55(1), 265-295.

Hong, H., \& Stein, J. (1999). A unified theory of underreaction, momentum trading, and overreaction in asset markets. The Journal of Finance, 54(6), 2143-2184.

Huang, D. (2006). Market states and international momentum strategies. Quarterly Review of Economics and Finance, 46(3), 437-446.

Jegadeesh, N. (1990). Evidence of predictable behavior of security returns. The Journal of Finance, 45(3), 881-898.

Jegadeesh, N., \& Titman, S. (1993). Returns to buying winners and selling losers: Implications for stock market efficiency. The Journal of Finance, 48(1), 65-91.

Jiang, G., Lee, C., \& Zhang, Y. (2005). Information uncertainty and expected returns. Review of Accounting Studies, 10(2), 185-221.

Kahneman, D., \& Frederick, S. (2002). Representativeness revisited: Attribute substitution in intuitive judgment. In T. Gilovich, D. Griffin (Eds.), Heuristics and biases: The psychology of Intuitive Judgment (pp. 49-81). New York: Cambridge University Press.

Kang, J., Liu, M., \& Ni, S. (2002). Contrarian and momentum strategies in the China stock market: 1993-2000. Pacific-Basin Finance Journal, 10(3), 243-265.

Kurov, A. (2008). Investor sentiment, trading behavior and informational efficiency in index futures markets. The Financial Review, 43(1), 107-127.

Lee, C., \& Swaminathan, B. (2000). Price momentum and trading volume. The Journal of Finance, 55(5), 2017-2069.

Lehmann, B. (1990). Fads, martingales, and market efficiency. The Quarterly Journal of Economics, 105(1), $1-28$.

Lin, A., \& Swanson, P. (2008). The effect of China's reform policies on stock market information transmission. Quarterly Journal of Finance and Accounting, 47(3), 49-76. 
Magnan, M., \& Xu, B. (2008). Information uncertainty, Corporate disclosure and stock return volatility. The SSRN. http://ssrn.com/abstract=1080618. Accessed Feb, 102016.

McKnight, P. J., \& Hou, T. C. T. (2006). The determinants of momentum in the United Kingdom. The Quarterly Review of Economics and Finance, 46(2), 227-240.

Moskowitz, T. J., \& Grinblatt, M. (1999). Do industries explain momentum? The Journal of Finance, 54(4), 1249-1290.

Naughton, T., Truong, C., \& Veeraraghavan, M. (2008). Momentum strategies and stock returns: Chinese evidence. Pacific-Basin Finance Journal, 16(4), 476-492.

Nisbett, R. E., Krantz, D. H., Jepson, C., \& Kunda, Z. (1983). The use of statistical heuristics in everyday inductive reasoning. Psychological Review, 90(4), 339-363.

Nofsinger, J., \& Sias, R. (1999). Herding and feedback trading by institutional and individual investors. The Journal of Finance, 54(6), 2263-2295.

Pena, J. I. (1995). Daily seasonalities and stock market reforms in Spain. Applied Financial Economics, 5(6), 419-423.

Rabin, M. (1997). Psychology and economics. Working paper, Berkeley Department of Economics, University of Berkeley No. 97-251.

Samuelson, W., \& Zeckhauser, R. (1988). Status quo bias in decision making. Journal of Risk and Uncertainty, $1(1), 7-59$.

Schultz, P. (2005). Discussion of "Information Uncertainty and Expected Returns". Review of Accounting Studies, 10(2), 223-226.

Schwarz, N. (1990). Feelings as information: Informational and motivational functions of affective states. In E. T. Higgins (Eds.), Handbook of motivation and cognition: Foundations of social behaviour (Vol. 2, pp. 527-561). New York: Guildford Press.

Siganos, A., \& Chelley-Steeley, P. (2006). Momentum profits following bull and bear markets. Journal of Asset Management, 6(5), 381-388.

Tversky, A., \& Kahneman, D. (1974). Judgment under uncertainty: Heuristics and biases. Science, 185(4157), 1124-1131.

Wang, F., \& Xu, Y. (2004). What determines Chinese stock returns? Financial Analysts Journal, 60(6), $65-77$.

Zhang, X. F. (2006). Information uncertainty and stock returns. The Journal of Finance, 61(1), 105-137. 